\title{
Effect of Age on Efficacy and Safety of Fluticasone Furoate/Vilanterol (FF/VI), Umeclidinium (UMEC), and UMEC + FF/VI in Patients with Chronic Obstructive Pulmonary Disease: Analyses of Five Randomized Clinical Trials
}

\author{
Nicola A Hanania (D) \\ Scott Caveney (D) $^{2}$ \\ Tedi Soule ${ }^{2}$ \\ Lee Tombs ${ }^{3}$ \\ Sally Lettis (D) $^{4}$ \\ Courtney Crim (iD) 5,6 \\ David M Mannino $\mathbb{1 D}^{7}$ \\ Hitesh Patel (1D ${ }^{2}$ \\ Isabelle $\mathrm{H}$ Boucot $\mathbb{D}^{4}$ \\ 'Airways Clinical Research Center, \\ Section of Pulmonary and Critical Care \\ Medicine, Baylor College of Medicine, \\ Houston, TX, USA; ${ }^{2}$ US Medical Affairs, \\ GlaxoSmithKline, Research Triangle Park, \\ NC, USA; ${ }^{3}$ Precise Approach Ltd, \\ Contingent Worker on Assignment at \\ GlaxoSmithKline, Brentford, Middlesex, \\ UK; ${ }^{4}$ Statistics, GlaxoSmithKline, \\ Brentford, Middlesex, UK; ${ }^{5}$ R\&D, \\ GlaxoSmithKline, Research Triangle Park, \\ NC, USA; ${ }^{6}$ Internal Medicine - Division of \\ Pulmonary and Critical Care Medicine, \\ University of North Carolina at Chapel \\ Hill, Chapel Hill, NC, USA; ${ }^{7}$ Department \\ of Preventive Medicine and \\ Environmental Health, University of \\ Kentucky, College of Public Health, \\ Lexington, KY, USA
}

Correspondence: Nicola A Hanania Airways Clinical Research Center, Section of Pulmonary and Critical Care Medicine, Baylor College of Medicine, Houston, TX, USA

Email hanania@bcm.edu
Introduction: Concerns have been raised about the practical use and clinical benefits of medications and inhalers in older patients with chronic obstructive pulmonary disease (COPD). Here, we report analyses according to age from five clinical trials evaluating medications administered using the ELLIPTA dry-powder inhaler (DPI).

Methods: Efficacy and safety according to age groups ( $<65$ and $\geq 65$ years) were assessed using data from five clinical trials in patients $\geq 40$ years of age with symptomatic COPD. There was a mix of pre-specified and post hoc analyses of two 24 -week trials with fluticasone furoate (FF)/vilanterol (VI) $100 / 25 \mu \mathrm{g}$; one 24-week trial with umeclidinium (UMEC) $62.5 \mu \mathrm{g}$; and two 12-week trials with UMEC $62.5 \mu \mathrm{g}+$ FF/VI 100/25 $\mu \mathrm{g}$. The primary endpoint was trough forced expiratory volume in 1 second $\left(\mathrm{FEV}_{1}\right)$ obtained 23 and 24 hours after dosing on the last day of the study.

Results: A total of 2876 patients $<65$ years of age and 2148 patients $\geq 65$ years of age were enrolled across all studies of whom 1333 and 1111 patients, respectively, received treatment at the doses presented. Statistically significant and clinically meaningful treatment differences in improvement from baseline in mean trough $\mathrm{FEV}_{1}$ were reported for active comparators versus placebo at study end for both $<65$ and $\geq 65$ years subgroups (FF/VI vs placebo: $143 \mathrm{~mL}$ and $111 \mathrm{~mL}$; UMEC vs placebo: $110 \mathrm{~mL}$ and $123 \mathrm{~mL}$; UMEC + FF/VI vs placebo + FF/VI: $136 \mathrm{~mL}$ and $105 \mathrm{~mL} ; \mathrm{p}<0.001$ for all comparisons). The incidence of adverse events reported for active treatments was similar between age groups.

Conclusion: These data provide evidence to support the use of FF/VI, UMEC, or UMEC + FF/VI, all delivered via the ELLIPTA DPI, to treat older ( $\geq 65$ years) and younger ( $<65$ years) patients with COPD.

Keywords: COPD, elderly, ELLIPTA dry-powder inhaler, fluticasone furoate/vilanterol, multiple-inhaler triple therapy, umeclidinium

\section{Plain Language Summary}

Why was the study done?

Chronic obstructive pulmonary disease (COPD) is more common in older adults. Due to biological changes that occur as people age, some medications that are commonly used to treat COPD may be less effective for older patients than younger patients. 


\section{What did the researchers do and find?}

We analyzed the results of five clinical trials for two groups: patients younger than 65 years, and patients older than 65 years. The study investigated whether three treatments (fluticasone furoate/vilanterol, umeclidinium, and umeclidinium + fluticasone furoate/vilanterol) improved patients' lung function for both age groups. We also explored whether there were any safety concerns in either age group. According to several different measures of lung function, all three treatments improved lung function in both younger patients (younger than 65 years) and older patients (65 years or older). The safety profile of all three treatments was acceptable in both age groups.

What do these results mean?

The results of this study support the use of fluticasone furoate/vilanterol, umeclidinium, and umeclidinium + fluticasone furoate/vilanterol to treat patients with COPD who are older than 65 years as well as those who are younger than 65 years.

\section{Introduction}

According to a population-based worldwide study, the prevalence of chronic obstructive pulmonary disease (COPD) increases steadily with age from approximately $\leq 5 \%$ in individuals aged $40-49$ years to $19-47 \%$ for men and $6-33 \%$ for women aged $\geq 70 .{ }^{1}$ In the US (2014-2015), $6.5 \%, 9.6 \%$, and $12.5 \%$ of adults aged $45-54,55-64$, and $\geq 65$ years, respectively, had physician-diagnosed COPD. ${ }^{2}$ In addition, older patients tend to have a greater disease burden compared with younger patients with COPD. ${ }^{3}$

Inhaled medications are the cornerstone of pharmacological therapy in the management of COPD. Differences may be observed in the pharmacokinetic or pharmacodynamic profile of medications between older and younger individuals due to age-related changes in physiology. ${ }^{4}$ Furthermore, older patients may find inhalers more difficult to use than younger patients due to functional and cognitive decline and comorbidities such as poor eyesight, arthritis, and impaired dexterity. ${ }^{5-7}$ Concerns have been raised about the use of certain formulations such as drypowder inhalers (DPIs) in older patients, who may have a considerably reduced ability to generate adequate inspiratory flow. ${ }^{5,8}$ Therefore, it is important to evaluate the efficacy and safety of COPD medications in older patients; however, this group is often under-represented in clinical trials. ${ }^{9,10}$

Previous post hoc analyses have evaluated the fixeddose combination long-acting muscarinic antagonist (LAMA)/long-acting $\beta_{2}$-agonist (LABA) umeclidinium (UMEC)/vilanterol (VI) in older patients. ${ }^{11}$ Consistent and significantly improved lung function compared with placebo was observed in older patients ( $\geq 65$ and $\geq 75$ years of age) with symptomatic COPD, with no notable diminution of the effect with advanced age. Furthermore, the safety profile for UMEC/VI was comparable in all age groups. A post hoc analysis of a study of inhalers containing placebo demonstrated that correct use and ease of use of the ELLIPTA DPI was similar in older patients $(\geq 65$ and $\geq 75$ years of age) compared with younger patients (40-64 years of age) with COPD. ${ }^{12}$

To help address the lack of clinical evidence on the efficacy and safety of inhaled medications for older adults with COPD, we investigated the effect of age by evaluating the lung function benefit and safety profile of several commonly used classes of inhaled medications for COPD in older patients ( $\geq 65$ years) compared with younger patients $(<65$ years). We report efficacy and safety results from subgroup analyses of several clinical trials with the fixed-dose combination inhaled corticosteroid (ICS)/ LABA fluticasone furoate (FF)/VI, the LAMA UMEC, and UMEC + FF/VI multiple-inhaler triple therapy (MITT), all administered once daily via the ELLIPTA DPI.

\section{Materials and Methods Study Designs}

Lung function benefits and safety according to age were analyzed in five multicenter, randomized, doubleblind, placebo-controlled, parallel-group clinical trials in patients with COPD. These included pre-planned and post hoc analyses from two 24-week studies with FF/VI, ${ }^{13-16}$ a post hoc analysis from one 24-week study with UMEC, ${ }^{17}$ and a post hoc analysis from two 12 -week studies with UMEC + FF/VI as MITT. ${ }^{18}$ Two age subgroups were evaluated $(<65$ and $\geq 65$ years). Additional age groups (such as $\geq 75$ years) were not evaluated due to insufficient sample sizes. Across all studies, treatments were administered once daily via the ELLIPTA DPI. Further details of study designs are presented in Table 1. Briefly, patients in all five studies had a clinical diagnosis of COPD, were $\geq 40$ years of age, had a smoking history of $\geq 10$ packyears, and a score of $\geq 2$ on the modified Medical Research Council Dyspnea Scale. ${ }^{13,15,17,18}$ In studies with FF/VI and UMEC, patients had a postbronchodilator forced expiratory volume in 1 second $\left(\mathrm{FEV}_{1}\right)$ /forced vital capacity $(\mathrm{FVC})$ ratio of $\leq 0.70$ or $<0.7$ and a post-bronchodilator $\mathrm{FEV}_{1} \leq 70 \%$ 
Table I Study Designs

\begin{tabular}{|c|c|c|c|c|c|}
\hline Study & Duration & $\begin{array}{l}\text { Key FEV, Endpoints and Days of } \\
\text { Assessment }\end{array}$ & $\begin{array}{l}\text { Randomization and } \\
\text { Stratification }\end{array}$ & Treatments $^{\mathbf{a}}$ & $\mathbf{N}$ \\
\hline \multicolumn{6}{|c|}{ Studies with FF/VI (ICS/LABA) } \\
\hline \multirow{5}{*}{$\begin{array}{l}\mathrm{HZCI} I 2206 \\
(\mathrm{NCTOI053988})^{13}\end{array}$} & \multirow{4}{*}{$\begin{array}{l}\text { Run-in } \\
2 \text { weeks, single-blind placebo } \\
\text { ELLIPTA }\end{array}$} & \multirow{4}{*}{$\begin{array}{l}\text { Trough } \text { FEV }_{1} \text { : } \\
\text { Days 2, 7, 14, 28, 56, 84, I I2, 140, 168, } 169 \\
\text { (co-primary endpoint) }\end{array}$} & \multirow{5}{*}{$\begin{array}{l}\text { I:I:I:I:I Stratified by } \\
\text { smoking status }\end{array}$} & Placebo & 207 \\
\hline & & & & FF $100 \mu g$ & 206 \\
\hline & & & & $\mathrm{VI} 25 \mu \mathrm{g}$ & 205 \\
\hline & & & & FF/VI 50/25 $\mu g^{\mathrm{b}}$ & 206 \\
\hline & $\begin{array}{l}\text { Treatment period } \\
24 \text { weeks, double-blind }\end{array}$ & $\begin{array}{l}\text { WM FEV , 0-4 hours post-dose: } \\
\text { Days I, I4, 56, 84, } 168 \text { (co-primary } \\
\text { endpoint) }\end{array}$ & & $\mathrm{FF} / \mathrm{VI} 100 / 25 \mu \mathrm{g}^{\mathrm{b}}$ & 206 \\
\hline \multirow{6}{*}{$\begin{array}{l}\mathrm{HZCI} I 2207 \\
(\mathrm{NCTOI054885})^{15}\end{array}$} & \multirow{4}{*}{$\begin{array}{l}\text { Run-in } \\
2 \text { weeks, single-blind placebo } \\
\text { ELLIPTA }\end{array}$} & \multirow{4}{*}{$\begin{array}{l}\text { Trough FEV } 1 \text { : } \\
\text { Days 2, 7, 14, 28, 56, 84, I12, 140, 168, } 169 \\
\text { (co-primary endpoint) }\end{array}$} & \multirow{6}{*}{$\begin{array}{l}\text { I:I:I:I:I:I Stratified by } \\
\text { smoking status }\end{array}$} & Placebo & 205 \\
\hline & & & & FF $100 \mu g$ & 204 \\
\hline & & & & FF $200 \mu g$ & 203 \\
\hline & & & & $\mathrm{VI} 25 \mu \mathrm{g}$ & 203 \\
\hline & \multirow{2}{*}{$\begin{array}{l}\text { Treatment period } \\
24 \text { weeks, double-blind }\end{array}$} & \multirow{2}{*}{$\begin{array}{l}\text { WM FEV, 0-4 hours post-dose: } \\
\text { Days I, I4, 56, 84, } 168 \text { (co-primary } \\
\text { endpoint) }\end{array}$} & & $\mathrm{FF} / \mathrm{VI} 100 / 25 \mu \mathrm{g}^{\mathrm{b}}$ & 204 \\
\hline & & & & FF/VI 200/25 $\mu g^{\mathrm{b}}$ & 205 \\
\hline \multicolumn{6}{|c|}{ Study with UMEC (LAMA) } \\
\hline \multirow{4}{*}{$\begin{array}{l}\text { DB2II3373 } \\
(\mathrm{NCT} 01313650)^{17}\end{array}$} & \multirow{3}{*}{$\begin{array}{l}\text { Run-in } \\
7-14 \text { days, albuterol as needed }\end{array}$} & \multirow{3}{*}{$\begin{array}{l}\text { Trough FEV } \\
\text { Days } 2,28,56,84,112,168,169 \text { (primary } \\
\text { endpoint) }\end{array}$} & \multirow[t]{4}{*}{$2: 3: 3: 3$} & Placebo & 280 \\
\hline & & & & UMEC $62.5 \mu g$ & 418 \\
\hline & & & & VI $25 \mu g$ & 421 \\
\hline & $\begin{array}{l}\text { Treatment period } \\
24 \text { weeks, double-blind }\end{array}$ & $\begin{array}{l}\text { WM FEV, 0-6 hours post-dose } \\
\text { Days I, 28, 84, } 168 \text { (secondary endpoint) }\end{array}$ & & UMEC/VI 62.5/25 $\mu \mathrm{g}$ & 413 \\
\hline \multicolumn{6}{|c|}{ Studies with UMEC + FF/VI (LAMA + ICS/LABA) } \\
\hline \multirow[t]{3}{*}{$\begin{array}{l}200109 \\
(\text { NCT0I957I63) }\end{array}$} & \multirow[t]{2}{*}{$\begin{array}{l}\text { Run-in } \\
4 \text { weeks, open-label FF/VI 100/25 } \mu g\end{array}$} & \multirow[t]{2}{*}{$\begin{array}{l}\text { Trough } \mathrm{FEV}_{\mathbf{l}} \text { : } \\
\text { Days 2, 28, 56, } 84,85 \text { (primary endpoint) }\end{array}$} & \multirow[t]{3}{*}{ I:I:I } & $\begin{array}{l}\text { Placebo + FF/VI I00/ } \\
25 \mu g\end{array}$ & 206 \\
\hline & & & & $\begin{array}{l}\text { UMEC } 62.5 \mu \mathrm{g}+\mathrm{FF} / \\
\mathrm{VI} 100 / 25 \mu \mathrm{g}\end{array}$ & 206 \\
\hline & $\begin{array}{l}\text { Treatment period } \\
\text { I } 2 \text { weeks, double-blind UMEC or } \\
\text { placebo, open-label FF/VI }\end{array}$ & $\begin{array}{l}\text { WM FEV, 0-6 hours post-dose } \\
\text { Days I, 28, } 84 \text { (secondary endpoint) }\end{array}$ & & $\begin{array}{l}\text { UMEC I } 25 \mu g^{c}+F F / \\
\text { VI } 100 / 25 \mu g\end{array}$ & 207 \\
\hline \multirow[t]{3}{*}{$\begin{array}{l}200110 \\
(\mathrm{NCT02} I 19286)^{18}\end{array}$} & $\begin{array}{l}\text { Run-in } \\
4 \text { weeks, open-label FF/VI 100/25 } \mu g\end{array}$ & $\begin{array}{l}\text { Trough FEV } \mathrm{I} \text { : } \\
\text { Days 2, 28, 56, 84, } 85 \text { (primary endpoint) }\end{array}$ & \multirow[t]{3}{*}{ I:I:I } & $\begin{array}{l}\text { Placebo + FF/VI I00/ } \\
25 \mu g\end{array}$ & 206 \\
\hline & \multirow[t]{2}{*}{$\begin{array}{l}\text { Treatment period } \\
12 \text { weeks, double-blind UMEC or } \\
\text { placebo, open-label FF/VI }\end{array}$} & \multirow[t]{2}{*}{$\begin{array}{l}\text { WM FEV, 0-6 hours post-dose } \\
\text { Days I, 28, } 84 \text { (secondary endpoint) }\end{array}$} & & $\begin{array}{l}\text { UMEC } 62.5 \mu \mathrm{g}+\mathrm{FF} / \\
\mathrm{VI} 100 / 25 \mu \mathrm{g}\end{array}$ & 206 \\
\hline & & & & $\begin{array}{l}\text { UMEC I } 25 \mu \mathrm{g}^{\mathrm{c}}+\mathrm{FF} / \\
\text { VI } 100 / 25 \mu \mathrm{g}\end{array}$ & 207 \\
\hline
\end{tabular}

Notes: ${ }^{a}$ Treatments in all studies were administered once daily via the ELLIPTA DPI. ${ }^{\mathrm{b} F F / V I ~ 100 / 25 \mu g}$ is the only licensed dose for COPD. ${ }^{\mathrm{C} U M E C ~} 62.5 \mu \mathrm{g}$ is the only licensed dose of UMEC.

Abbreviations: COPD, chronic obstructive pulmonary disease; DPI, dry-powder inhaler; FEV corticosteroid; LABA, long-acting $\beta_{2}$-agonist; LAMA, long-acting muscarinic antagonist; UMEC, umeclidinium; VI, vilanterol; WM, weighted mean.

predicted. ${ }^{13,15,17,18}$ Patients were not required to have a prior history of exacerbations. Patients were excluded if they had a current diagnosis of asthma or other known respiratory disease or use of long-term oxygen therapy. Full inclusion and exclusion criteria have been published previously. ${ }^{13,15,17,18}$

Data from all treatment arms in each study were included in the analyses; however, data for approved 
products and doses are the focus of this manuscript: FF/VI $100 / 25 \mu \mathrm{g}$ versus placebo; UMEC $62.5 \mu \mathrm{g}$ versus placebo; and UMEC $62.5 \mu \mathrm{g}+\mathrm{FF} / \mathrm{VI} 100 / 25 \mu \mathrm{g}$ versus placebo + FF/VI 100/25 $\mu \mathrm{g}$.

All studies were conducted in accordance with the Declaration of Helsinki and were approved by the relevant local ethics review committees. All patients provided written, informed consent before study participation. ${ }^{13,15,17,18}$

\section{Endpoints}

Across all studies, lung function was evaluated via spirometry at each study visit (Table 1). ${ }^{13,15,17,18}$ The primary efficacy endpoint was change from baseline in trough $\mathrm{FEV}_{1}$ at study end (Day 169 in studies with UMEC and FF/VI and Day 85 in studies with UMEC $+\mathrm{FF} /$ VI). ${ }^{13,15,17,18}$ Baseline $\mathrm{FEV}_{1}$ was defined as the mean of the two $\mathrm{FEV}_{1}$ assessments obtained 30 and 5 minutes predose on Day 1. Trough $\mathrm{FEV}_{1}$ was defined as the mean $\mathrm{FEV}_{1}$ value obtained 23 and 24 hours after dosing on the last day of the study. Weighted mean (WM) $\mathrm{FEV}_{1}$ 0-4 hours post-dose on Day 168 was assessed as a co-primary endpoint in studies with FF/VI; WM FEV 1 0-6 hours post-dose on Day 168 in the study with UMEC and on Day 84 in studies with UMEC + FF/VI was assessed as a secondary endpoint. ${ }^{13,15,17,18}$

Other efficacy endpoints included trough $\mathrm{FEV}_{1}$ and $\mathrm{WM} \mathrm{FEV}_{1}$ at other time points; proportion of trough $\mathrm{FEV}_{1}$ responders at all time points; ratio of $\mathrm{FEV}_{1}$ to baseline (ie, percent change in $\mathrm{FEV}_{1}$ ) at all time points; and change from baseline in trough FVC throughout the study. Response for $\mathrm{FEV}_{1}$ was defined as $\geq 100 \mathrm{~mL}$ improvement from baseline. Ratio of $\mathrm{FEV}_{1}$ to baseline was calculated to account for differences in baseline lung function that may be associated with aging. Baseline FVC was defined as the mean of the two assessments made 30 minutes and either 5 minutes or immediately pre-dose on Day 1 .

Safety was evaluated using summaries of adverse events (AEs), common on-treatment AEs and selected AEs of interest.

\section{Statistical Analysis}

All analyses were conducted on the intent-to-treat (ITT) populations, which included all patients randomized to treatment who received $\geq 1$ dose of study medication. All endpoints were analyzed by age subgroups of $<65$ and $\geq 65$ years.

Pooled data from the two studies evaluating FF/VI and the two studies evaluating UMEC + FF/VI as MITT were used. For the studies with UMEC and UMEC + FF/VI, all analyses by age subgroups were performed post hoc. For studies with $\mathrm{FF} / \mathrm{VI}$, analyses of trough $\mathrm{FEV}_{1}$, WM FEV $\mathrm{W}_{1} 0-4$ hours and safety by age subgroup were pre-planned; analyses of trough $\mathrm{FEV}_{1}$ responders, ratio of $\mathrm{FEV}_{1}$ to baseline, and change from baseline in trough FVC were conducted post hoc.

Analyses of trough $\mathrm{FEV}_{1}, \mathrm{WM} \mathrm{FEV}_{1}$ and trough $\mathrm{FVC}$ were performed using a repeated measures model. Analysis of trough $\mathrm{FEV}_{1}$ responders was performed using a generalized linear mixed model with a logit link function. Ratio of $\mathrm{FEV}_{1}$ versus baseline analysis was performed using a repeated measures model, with response of log (trough $\mathrm{FEV}_{1} /$ baseline $\mathrm{FEV}_{1}$ ); results were back transformed to provide point estimates for the ratios. All analyses included specific covariates (Supplementary Table 1).

\section{Results}

\section{Baseline Characteristics}

A total of 5024 patients were included across all studies and treatment groups, of whom 2876 (57\%) patients were $<65$ years of age (range: $40-64$ years) and 2148 (43\%) patients were $\geq 65$ years of age (range: 65-93 years). The majority of patients in both age groups were male, with a slightly higher proportion of males in the $\geq 65$ years group (Table 2). Patients in both age groups had a substantial smoking history ( $\geq 40$ packyears). Approximately two-thirds of patients in the $<65$ years age group and approximately one-third of patients in the $\geq 65$ years group were current smokers. The majority of patients $(\geq 70 \%)$ did not have a moderate or severe exacerbation in the 12 months prior to screening. Both age groups, on average, had severe airflow limitation at screening with a mean percent predicted postbronchodilator $\mathrm{FEV}_{1}$ of approximately $47 \%$ (range: 13-87\%). Post-bronchodilator FEV $\mathrm{F}_{1}$ and FVC at screening were lower in the $\geq 65$ years of age subgroup compared with the $<65$ years of age subgroup. A total of 2444 patients were included in the treatment groups presented in this article, of whom 1333 were $<65$ years of age and 1111 were $\geq 65$ years of age.

\section{Trough FEV ,}

Across all studies, significant and clinically meaningful improvements from baseline in trough $\mathrm{FEV}_{1}$ at study end were reported for the active comparator compared with placebo for both age subgroups (Table 3). Treatment differences in mean change from baseline in trough $\mathrm{FEV}_{1}$ for $\mathrm{FF} / \mathrm{VI}$ versus placebo, UMEC versus placebo, and UMEC 
Table 2 Demographics and Baseline Characteristics

\begin{tabular}{|c|c|c|c|c|c|c|}
\hline \multirow{2}{*}{$\begin{array}{l}\text { Demographic and Baseline } \\
\text { Characteristics } \\
\text { Age Group }\end{array}$} & \multicolumn{2}{|c|}{$\begin{array}{c}\text { Two 24-Week Studies with FF/VI } \\
\text { (HZCII2206 and HZCII } 2207 \\
\text { Pooled) }\end{array}$} & \multicolumn{2}{|c|}{$\begin{array}{l}\text { 24-Week Study with UMEC } \\
\text { (DB2 I 13373) }\end{array}$} & \multicolumn{2}{|c|}{$\begin{array}{l}\text { Two I2-Week Studies with UMEC } \\
\text { + FF/VI (200 I09 and 200II } 0 \\
\text { Pooled) }\end{array}$} \\
\hline & $<65$ Years & $\geq 65$ Years & $<65$ Years & $\geq 65$ Years & $<65$ years & $\geq 65$ Years \\
\hline$N$ & 1339 & 915 & 867 & 665 & 670 & 568 \\
\hline Age, years, mean (range) & $56.2(40,64)$ & $70.8(65,85)$ & $56.9(40,64)$ & $71.2(65,93)$ & $57.6(42,64)$ & $70.8(65,88)$ \\
\hline Male, n (\%) & $882(66)$ & $688(75)$ & $589(68)$ & $494(74)$ & $4 \mid 2(6 \mid)$ & $386(68)$ \\
\hline Current smoker, n (\%) & $882(66)$ & $340(37)$ & $551(64)$ & $208(31)$ & $418(62)$ & $195(34)$ \\
\hline $\begin{array}{l}\text { Smoking history, pack-years, mean } \\
\text { (range) }\end{array}$ & $41.2(10,200)$ & $48.5(10,196)$ & $43.1(10,136)$ & $50.2(10,225)$ & $45.1(10,166)$ & $51.1(10,200)$ \\
\hline $\begin{array}{l}\text { Post-BD FEV , at screening, } \mathrm{mL} \text {, mean } \\
\text { (SD) }\end{array}$ & $1555(504)$ & $1300(410)$ & $1502(54 \mid)$ & $1232(390)$ & 1459 (509) & $|21|(394)$ \\
\hline $\begin{array}{l}\text { Percent predicted post-BD FEV , at } \\
\text { screening, mean (range) }\end{array}$ & $48.1(14,87)$ & $48.1(14,77)$ & $47.4(13,74)$ & $47.6(16,70)$ & $46.4(13,70)$ & $46.0(17,76)$ \\
\hline Percent FEV, reversibility, mean (SD) & $13.2(15.3)$ & $14.7(16.5)$ & $14.7(15.7)$ & $14.5(14.6)$ & $13.4(12.8)$ & $13.1(12.3)$ \\
\hline $\begin{array}{l}\text { Post-BD FVC at screening, } \mathrm{mL} \text {, mean } \\
\text { (SD) }\end{array}$ & $3236(911)$ & $2947(817)$ & $3133(884)$ & $2700(716)$ & $2939(830)$ & $2588(700)$ \\
\hline \multicolumn{7}{|l|}{$\begin{array}{l}\text { Exacerbation history in previous } \\
12 \text { months, } n(\%)\end{array}$} \\
\hline$\geq 1$ moderate $^{\mathrm{a}}$ & $318(24)$ & $229(25)$ & $256(30)$ & $166(25)$ & $84(13)$ & $95(17)$ \\
\hline$\geq \mid$ severe $^{b}$ & $126(9)$ & $67(7)$ & $114(13)$ & $60(9)$ & $22(3)$ & $12(2)$ \\
\hline
\end{tabular}

Notes: ${ }^{\text {a }}$ equiring oral/systemic corticosteroids and/or antibiotics; ${ }^{\mathrm{b}}$ Requiring hospitalization.

Abbreviations: $\mathrm{BD}$, bronchodilator; $\mathrm{FEV}$, forced expiratory volume in I second; FVC, forced vital capacity; SD, standard deviation; FF, fluticasone furoate; UMEC, umeclidinium; VI, vilanterol.

$+\mathrm{FF} / \mathrm{VI}$ versus placebo $+\mathrm{FF} / \mathrm{VI}$ at study end were $143 \mathrm{~mL}, 110 \mathrm{~mL}$, and $136 \mathrm{~mL}$, respectively, for patients $<65$ years of age; and $111 \mathrm{~mL}, 123 \mathrm{~mL}$, and $105 \mathrm{~mL}$, respectively, for patients $\geq 65$ years of age $(p<0.001$ for all comparisons).

Across all studies, significant improvements from baseline in trough $\mathrm{FEV}_{1}$ were reported for $\mathrm{FF} / \mathrm{VI}$, UMEC, or $\mathrm{UMEC}+\mathrm{FF} / \mathrm{VI}$ compared with placebo (placebo $+\mathrm{FF} / \mathrm{VI}$ for $\mathrm{UMEC}+\mathrm{FF} / \mathrm{VI}$ treatment arm) at all time points (Figure 1).

\section{WM FEV,}

Statistically significant improvements from baseline in WM $\mathrm{FEV}_{1}$ over $0-4$ or $0-6$ hours at study end were reported for the active comparator compared with placebo for both age subgroups (Table 3). Significant improvements from baseline in $\mathrm{WM} \mathrm{FEV}_{1}$ over $0-4$ or $0-6$ hours were also reported for the active comparators versus placebo at all time points across all studies (Supplementary Figure 1).

\section{FEV, Responders}

Patients in both age subgroups had significantly greater odds of a clinically meaningful improvement from baseline $(\geq 100 \mathrm{~mL})$ in trough $\mathrm{FEV}_{1}$ with active treatment compared with placebo across all studies $(\mathrm{p} \leq 0.002$ at all time points) (Figure 2). The odds of being a responder were similar in the $<65$ and $\geq 65$ years of age subgroups for patients treated with FF/VI.

\section{Trough FEV / $/$ Baseline FEV, Ratio}

As post-bronchodilator $\mathrm{FEV}_{1}$ at screening was lower in the $\geq 65$ years subgroup than in the $<65$ years subgroup (Table 2), the ratio of trough $\mathrm{FEV}_{1}$ to baseline $\mathrm{FEV}_{1}$ was compared with account for differences in baseline lung function that may be associated with aging. Across the active treatment arms of all studies, in both age subgroups, the increase in trough $\mathrm{FEV}_{1}$ was approximately $10 \%$ (Table 3). Significant improvements in the ratio of trough $\mathrm{FEV}_{1}$ to baseline $\mathrm{FEV}_{1}$ were reported for active treatment 


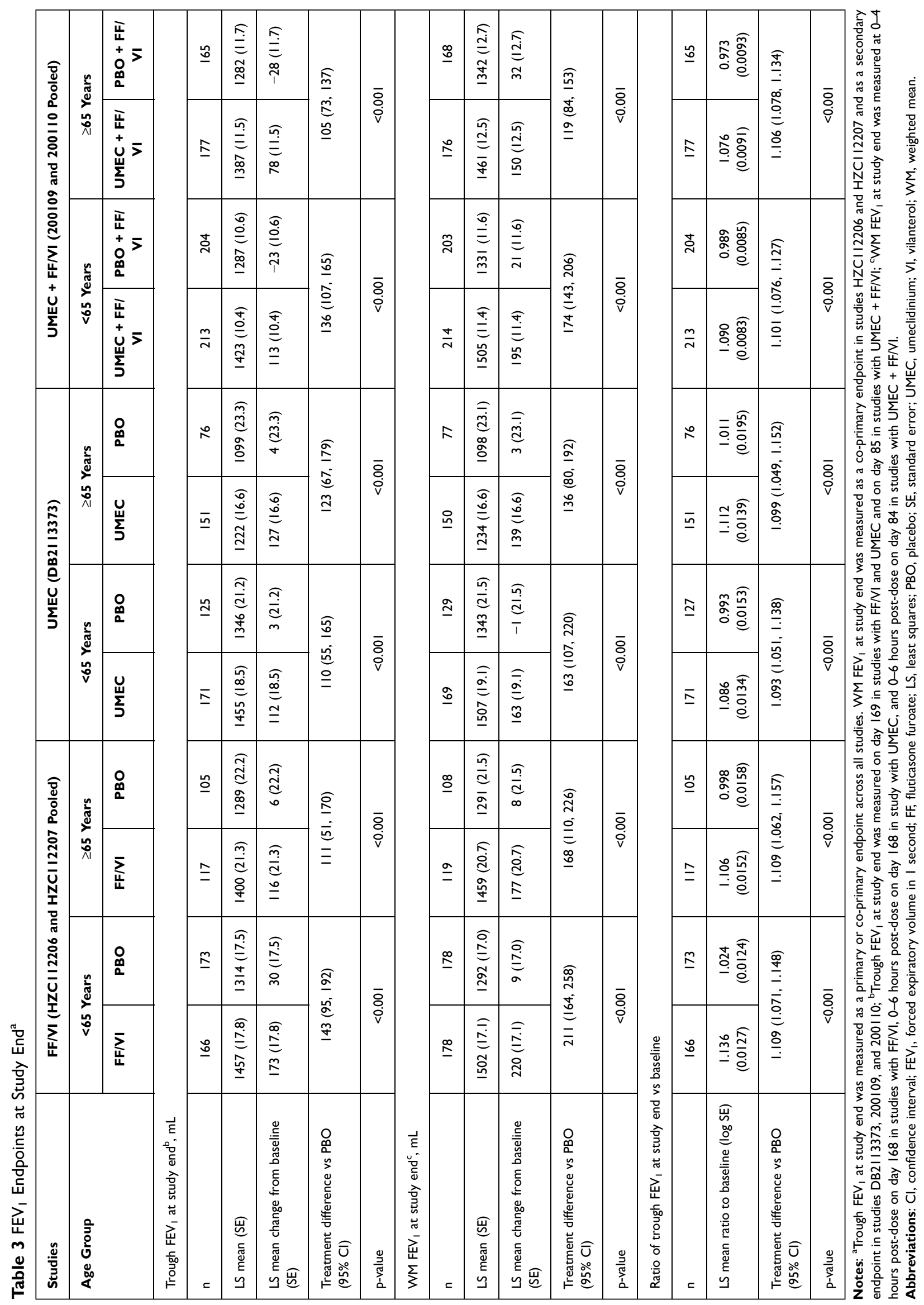




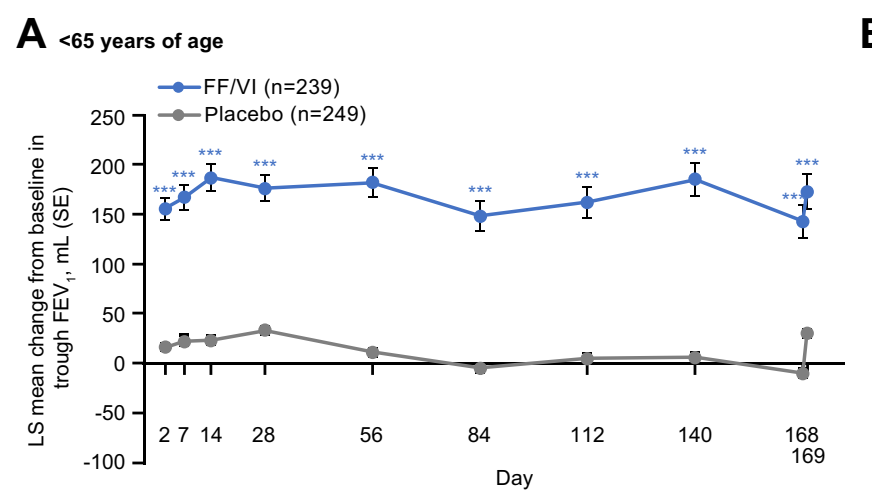

\section{$B \geq 65$ years of age}

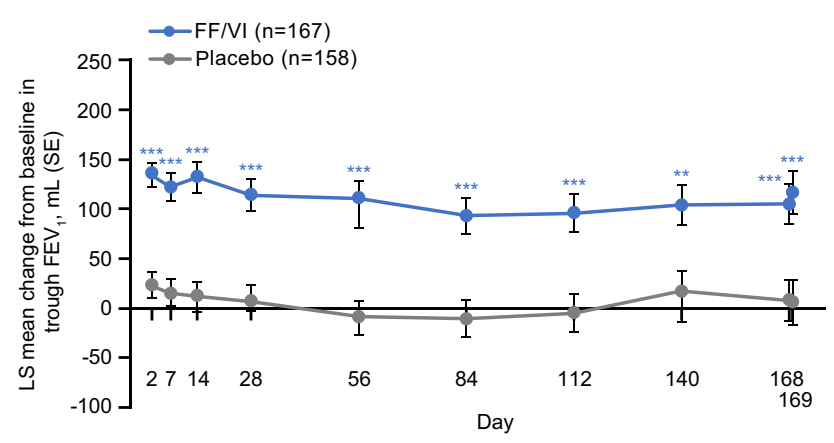

C $<65$ years of age

$D \geq 65$ years of age
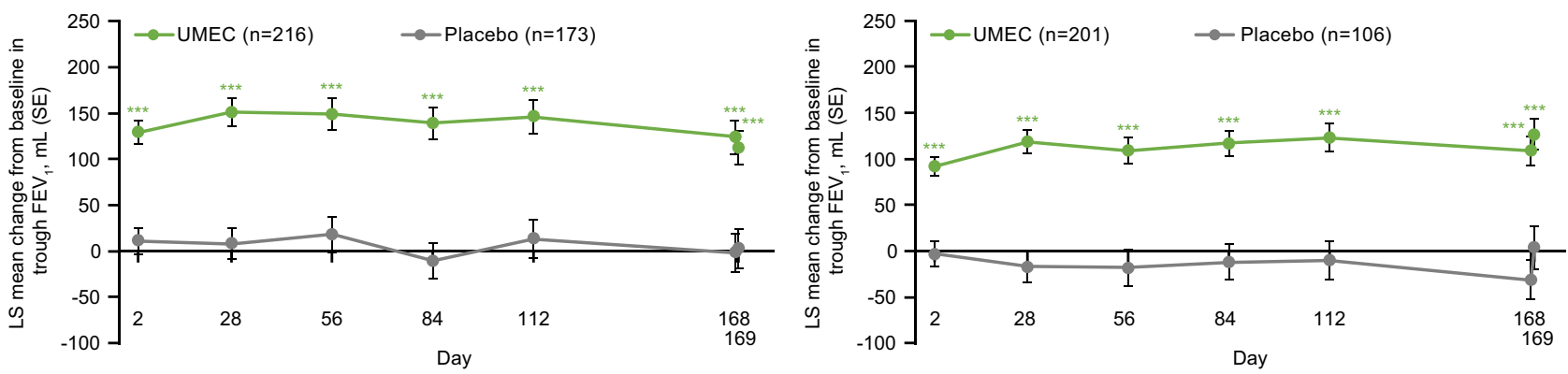

E $<65$ years of age

$F \geq 65$ years of age
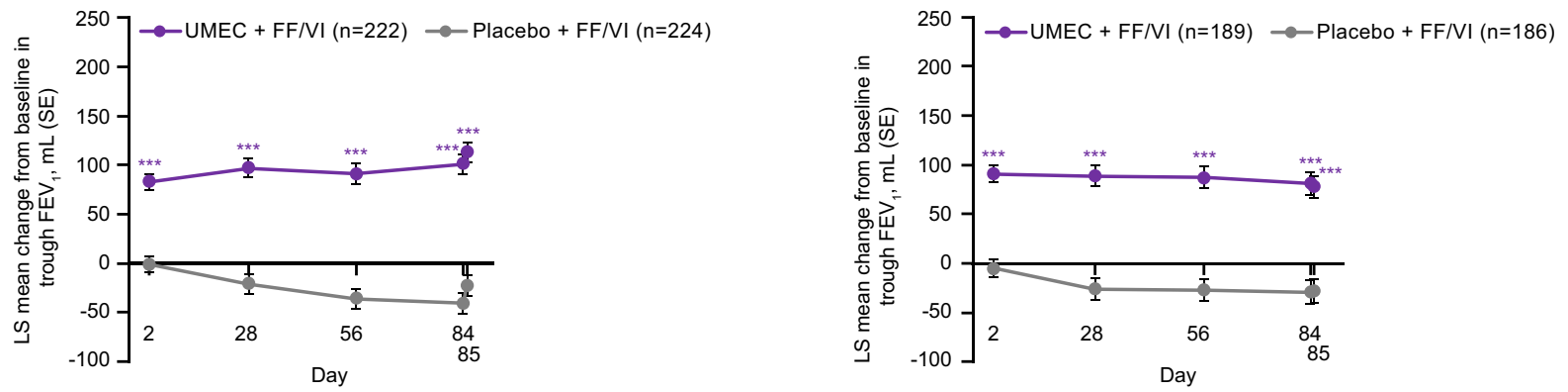

Figure I Change from baseline in trough FEV , over the course of the studies comparing FF/VI versus placebo (A and $\mathbf{B})$, UMEC versus placebo $(\mathbf{C}$ and $\mathbf{D})$, and UMEC + FF/ $\mathrm{VI}$ versus placebo $+\mathrm{FF} / \mathrm{VI}(\mathbf{E}$ and $\mathbf{F})$. $n=$ number of patients with data available for at least I time point; *** $\leq \leq 0.00 \mathrm{I}$ vs placebo.

Abbreviations: $\mathrm{FEV}_{\mathrm{I}}$, forced expiratory volume in I second; FF, fluticasone furoate; LS, least squares; SE, standard error; UMEC, umeclidinium; VI, vilanterol.

arms compared with placebo arms at all time points across all studies ( $<<0.001$ for all comparisons) (Figure 3 ).

\section{Trough FVC}

Across all studies, mean post-bronchodilator FVC at screening was approximately $300-400 \mathrm{~mL}$ lower in the $\geq 65$ years age subgroup compared with the $<65$ years age subgroup (Table 2). Statistically significant improvements from baseline in trough FVC were observed with FF/VI versus placebo in the $<65$ years subgroup at study end (107 mL; $\mathrm{p}=0.017$ ) (Table 4) and at all other time points (Supplementary Figure 2A). In the $\geq 65$ years subgroup, statistically significant improvements from baseline in trough $\mathrm{FVC}$ were observed with $\mathrm{FF} / \mathrm{VI}$ versus placebo at
Days $2,7,14,28$, and 56, with a numerical trend in favor of FF/VI at Days 84, 112, 140, and 168 (Supplementary Figure 2B), and the end of the study ( $45 \mathrm{~mL} ; \mathrm{p}=0.334$ ) (Table 4). There were statistically significant improvements from baseline in trough FVC for UMEC and $\mathrm{UMEC}+\mathrm{FF} / \mathrm{VI}$ compared with placebo (placebo $+\mathrm{FF} / \mathrm{VI}$ for UMEC + FF/VI treatment arm) for both age subgroups at study end (Table 4) and at all other time points (Supplementary Figure 2C-F).

\section{Safety}

Nasopharyngitis, headache, and upper respiratory tract infection were the most common AEs reported for patients in the active treatment and placebo arms across all studies 
A

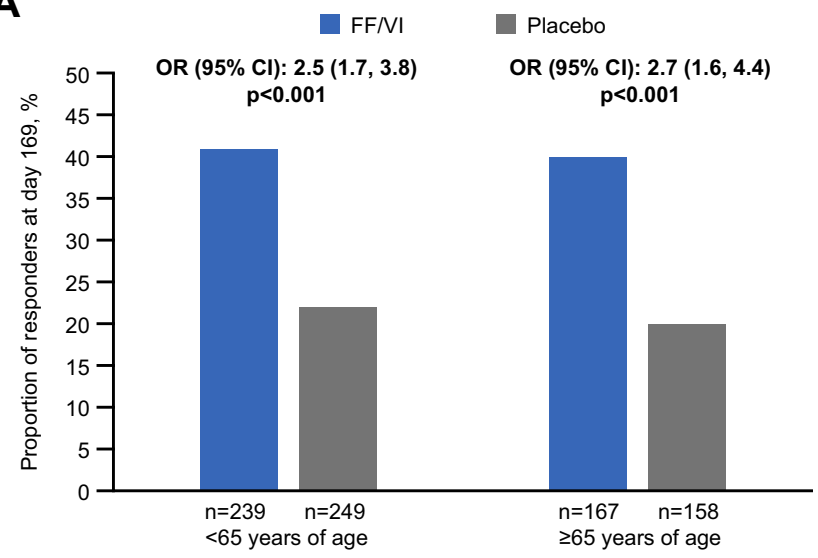

C

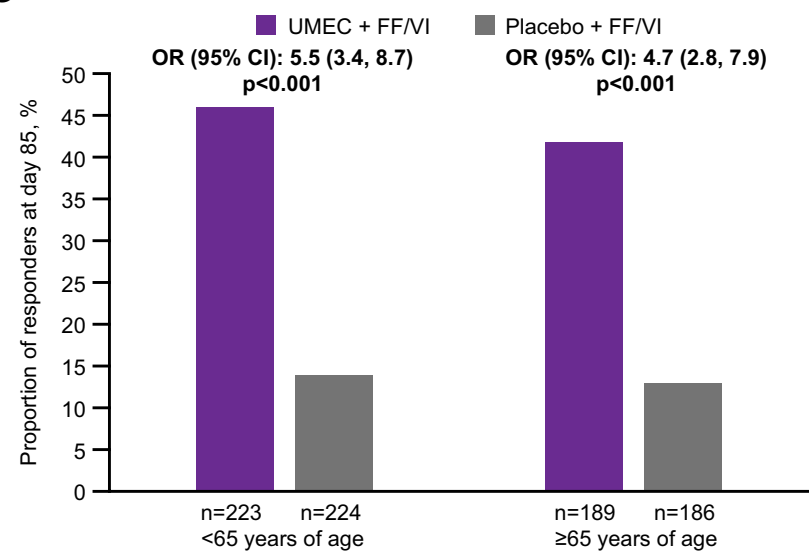

B

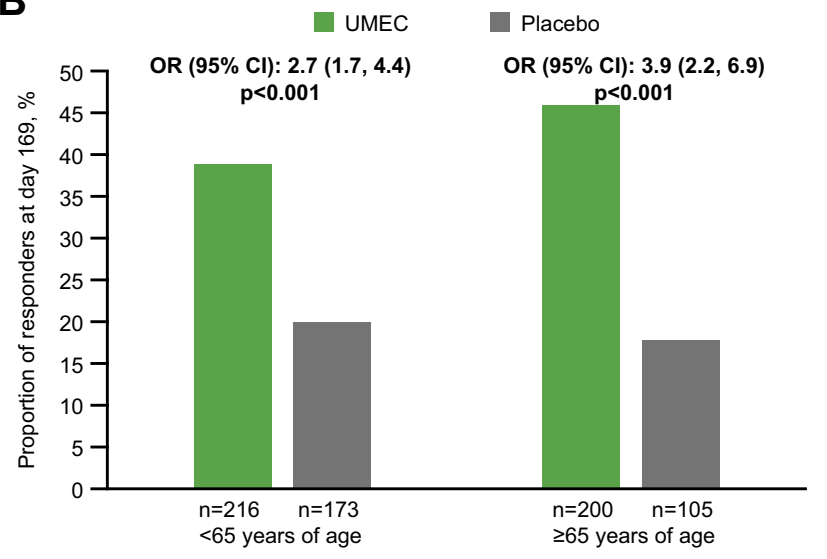

Figure $2 \mathrm{FEV}$, responders ( $\geq 100 \mathrm{~mL}$ improvement from baseline in trough FEVI) at study end in studies comparing FF/VI versus placebo (A), UMEC versus placebo (B), and $\mathrm{UMEC}+\mathrm{FF} / \mathrm{VI}$ versus placebo + FF/VI (C).

Abbreviations: $\mathrm{Cl}$, confidence interval; $\mathrm{FEV}_{\mathrm{l}}$, forced expiratory volume in I second; FF, fluticasone furoate; OR, odds ratio; UMEC, umeclidinium; $\mathrm{VI}$, vilanterol.

(Table 5). Overall, the incidences of other AEs of interest (including oral/oropharyngeal candidiasis, pneumonia, cardiac/vascular events, renal/urinary, and eye events) were similar between age subgroups for all studies. For both age subgroups, pneumonia was reported for $\leq 2 \%$ patients in the active comparator arms and $\leq 1 \%$ of patients in the placebo arms across all studies. Cardiac events were reported for $\leq 6 \%$ of patients in the active treatment arms and $\leq 11 \%$ of patients in the placebo arms; vascular events were reported for $\leq 3 \%$ of patients in the placebo and active treatment arms across both age groups.

\section{Discussion}

These analyses of five 12- and 24-week clinical studies demonstrate improvement in lung function and safety of several commonly used classes of inhaled medications delivered once daily via the ELLIPTA DPI compared with placebo in younger ( $<65$ years) and older $(\geq 65$ years) patients with COPD.
Each $\mathrm{FEV}_{1}$ endpoint analyzed highlighted distinct aspects of lung function improvement with FF/VI, UMEC, and UMEC + FF/VI as MITT. First, consistent and statistically significant improvements from baseline in $\mathrm{WM} \mathrm{FEV}_{1}$ at $0-4$ hours or $0-6$ hours post-dose compared with placebo in both age subgroups confirmed the effect of treatment within the first few hours after dosing. Second, consistent and statistically significant improvements from baseline in trough $\mathrm{FEV}_{1}$ compared with placebo in both age subgroups demonstrated that the effect of treatment was sustained over 24 hours. Furthermore, a significantly greater proportion of patients achieved a clinically relevant improvement in trough $\mathrm{FEV}_{1}(\geq 100 \mathrm{~mL}$ increase from baseline) with FF/VI, UMEC, and UMEC + FF/VI compared with placebo for both age subgroups.

The greater odds of a $\mathrm{FEV}_{1}$ response with UMEC versus placebo in the $\geq 65$ years of age subgroup compared with the $<65$ years of age subgroup suggest that older patients may be more responsive to UMEC monotherapy than younger patients. 


\section{$A<65$ years of age}

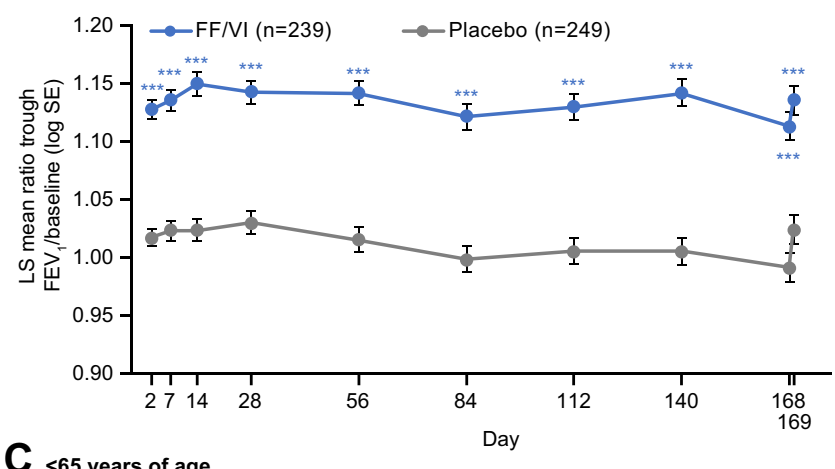

C <65 years of age

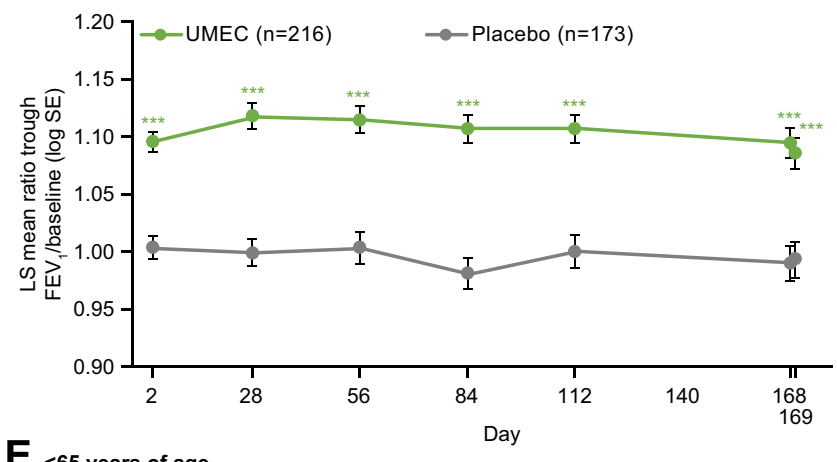

$E<65$ years of age

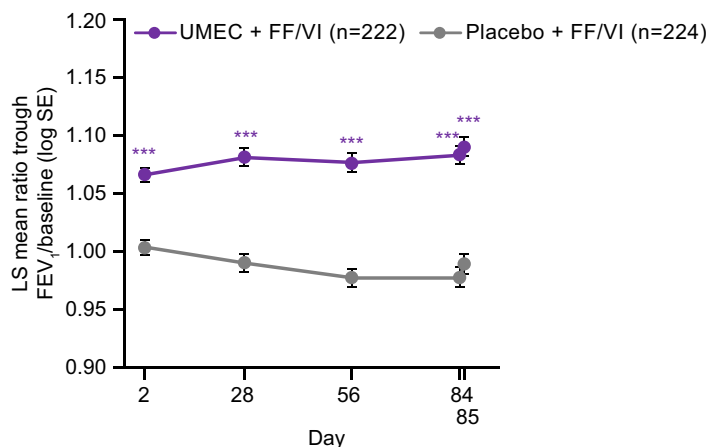

\section{$B \geq 65$ years of age}

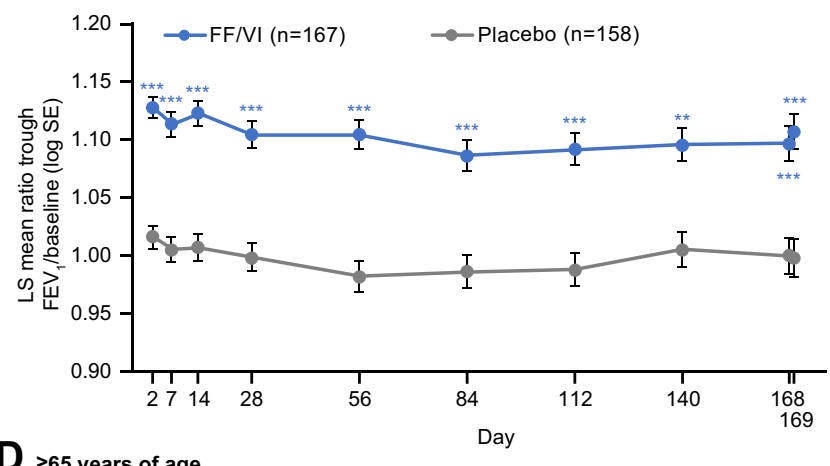

$D \geq 65$ years of age

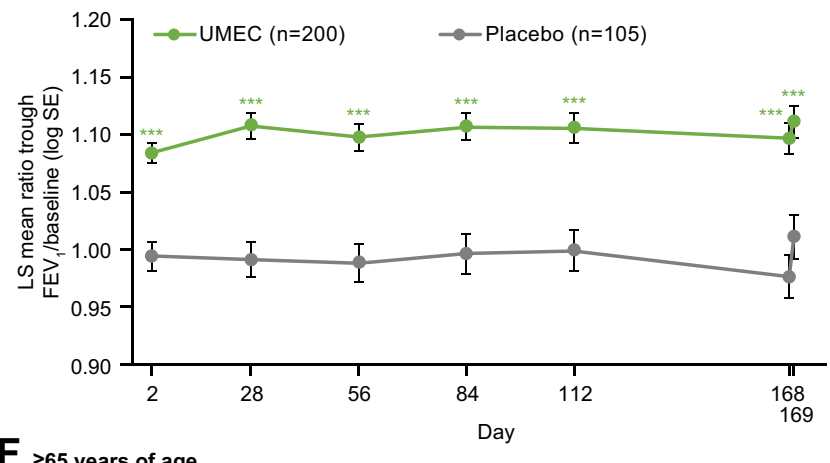

$\mathbf{F} \geq 65$ years of age

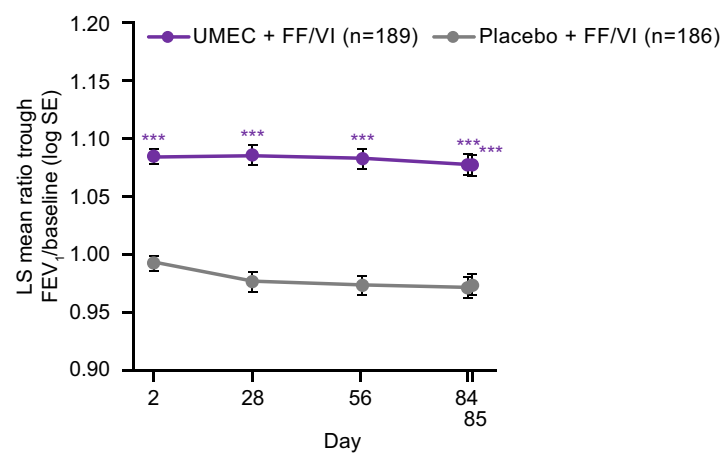

Figure 3 Ratio of trough $\mathrm{FEV}_{1}$ /baseline $\mathrm{FEV}$, over the course of the studies comparing FF/VI versus placebo (A and $\left.\mathbf{B}\right)$, UMEC versus placebo (C and $\left.\mathbf{D}\right)$, and UMEC + FF/VI versus placebo + FF/VI (E and $\mathbf{F})$. $n=$ number of patients with data available for at least I time point; *** $\leq 0.00 \mathrm{I}$ vs placebo.

Abbreviations: $\mathrm{FEV}_{\mathrm{l}}$, forced expiratory volume in I second; FF, fluticasone furoate; LS, least squares; SE, standard error; UMEC, umeclidinium; VI, vilanterol.

It is noteworthy that a similar trend was observed in previous analyses of UMEC/VI versus placebo in older patients with COPD. ${ }^{11}$ However, the lower odds of a $\mathrm{FEV}_{1}$ response with $\mathrm{UMEC}+\mathrm{FF} / \mathrm{VI}$ versus placebo $+\mathrm{FF} / \mathrm{VI}$ in the $\geq 65$ years of age subgroup compared with the $<65$ years of age subgroup do not support this finding. This raises the possibility that bronchodilator monotherapy (LAMA) or dual therapy (LAMA/LABA) may be more appropriate treatment options than ICS/LABA in elderly symptomatic patients at low exacerbation risk, where the goal of treatment is to improve lung function and reduce symptoms; however, further studies are required to confirm this observation and further investigate the effect of age on the efficacy of MITT and single-inhaler triple therapy.
In this analysis, UMEC demonstrated statistically significant improvements from baseline in trough $\mathrm{FVC}$ versus placebo that were sustained throughout the entire treatment period for both age groups. Statistically significant improvements from baseline in trough FVC for FF/VI versus placebo were also observed in the $<65$ years subgroup throughout the entire study period. In the $\geq 65$ years subgroup, numerical improvements from baseline in trough FVC for FF/VI versus placebo were observed throughout the entire treatment period, although these differences were only statistically significant until Day 56. This evidence further suggests that bronchodilator therapy may be a more appropriate treatment option than 


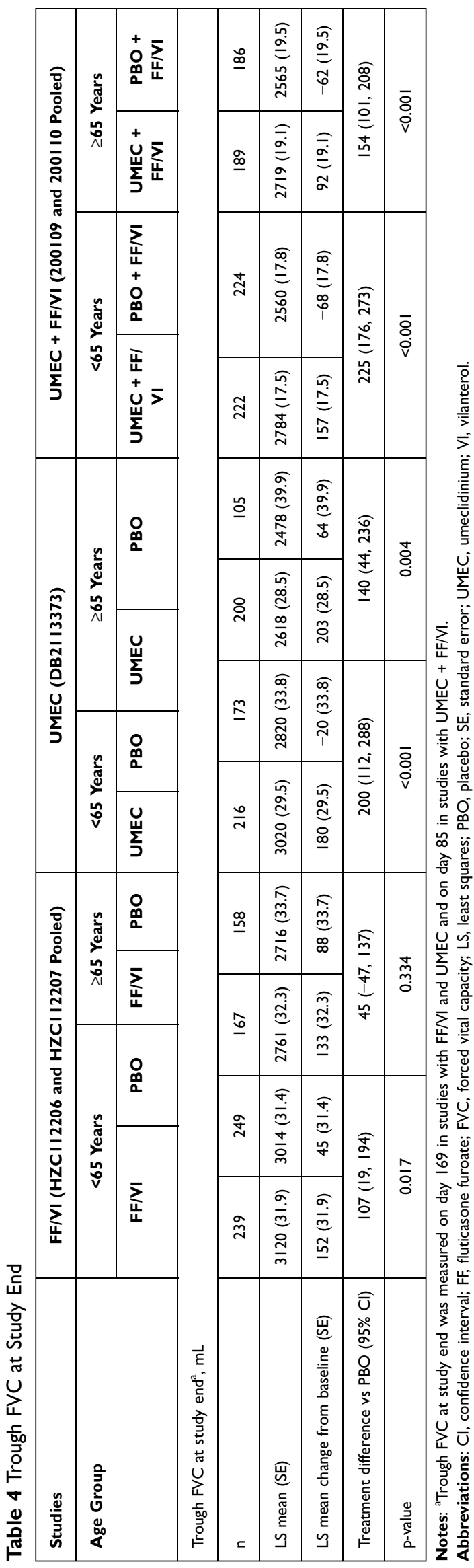

ICS/LABA in elderly patients where the goal of treatment is to improve lung function.

Across these analyses, as expected, lung function at screening was lower in the $\geq 65$ years subgroup compared with the $<65$ years subgroup. ${ }^{5,19,20}$ To account for differences in baseline lung function, we calculated the ratio of each $\mathrm{FEV}_{1}$ measurement to baseline $\mathrm{FEV}_{1}$. Across all studies at all time points, $\mathrm{FEV}_{1}$ ratios for FF/VI, UMEC, and UMEC + FF/VI were similar between age subgroups and statistically significant compared with placebo. This further supports a consistent $\mathrm{FEV}_{1}$ improvement in both age subgroups, despite the lower mean $\mathrm{FEV}_{1}$ at baseline in older patients. Concerns have been raised about the use of DPIs in older patients because the ability to generate adequate inspiratory flow may be reduced in these patients. ${ }^{6,11}$ In this study, all treatments were delivered using the ELLIPTA DPI, a device that has demonstrated consistency of delivered dose and fine particle mass fraction at flows of between $30 \mathrm{~L} / \mathrm{min}$ and $90 \mathrm{~L} / \mathrm{min}^{21,22}$ Patients with COPD and a $\mathrm{FEV}_{1}<30 \%$ predicted have demonstrated the ability to generate peak inspiratory flows of at least $41.6-52 \mathrm{~L} / \mathrm{min} .^{23,24}$ The consistency of findings across our analyses suggests that there is no apparent reduction in the benefit of inhaled treatments delivered via the ELLIPTA DPI for $\mathrm{FEV}_{1}$ outcomes in patients $\geq 65$ years of age; however, patients' inspiratory flow was not measured in our studies. Our findings are in line with a previous study that demonstrated no diminution of effect of UMEC/VI delivered via ELLIPTA DPI on lung function in older patients with COPD ( $\geq 65$ or $\geq 75$ years of age). ${ }^{11}$ Furthermore, a recent analysis of the IMPACT trial also demonstrated that the safety and efficacy of FF/UMEC/VI delivered by a single inhaler (ELLIPTA DPI) across three age subgroups ( $\leq 64,65-74$ and $\geq 75$ years) were generally consistent with those reported in the overall ITT population. ${ }^{25}$ Together these results suggest that the ELLIPTA DPI is suitable for older patients; however, further studies are required to assess other DPIs.

It is also important to consider the safety of medications prescribed in older patients. ${ }^{4}$ The AE profiles and incidence of AEs of interest were similar between age subgroups across all studies; however, small differences between treatments, low incidence of AEs, and different duration of the studies preclude us from making any conclusions.

Our analyses are not without limitations. First, many of the analyses were post hoc; therefore, comparisons within groups were not adequately powered therefore statistical analyses should be interpreted with caution. Second, since studies included in these analyses were all randomized 


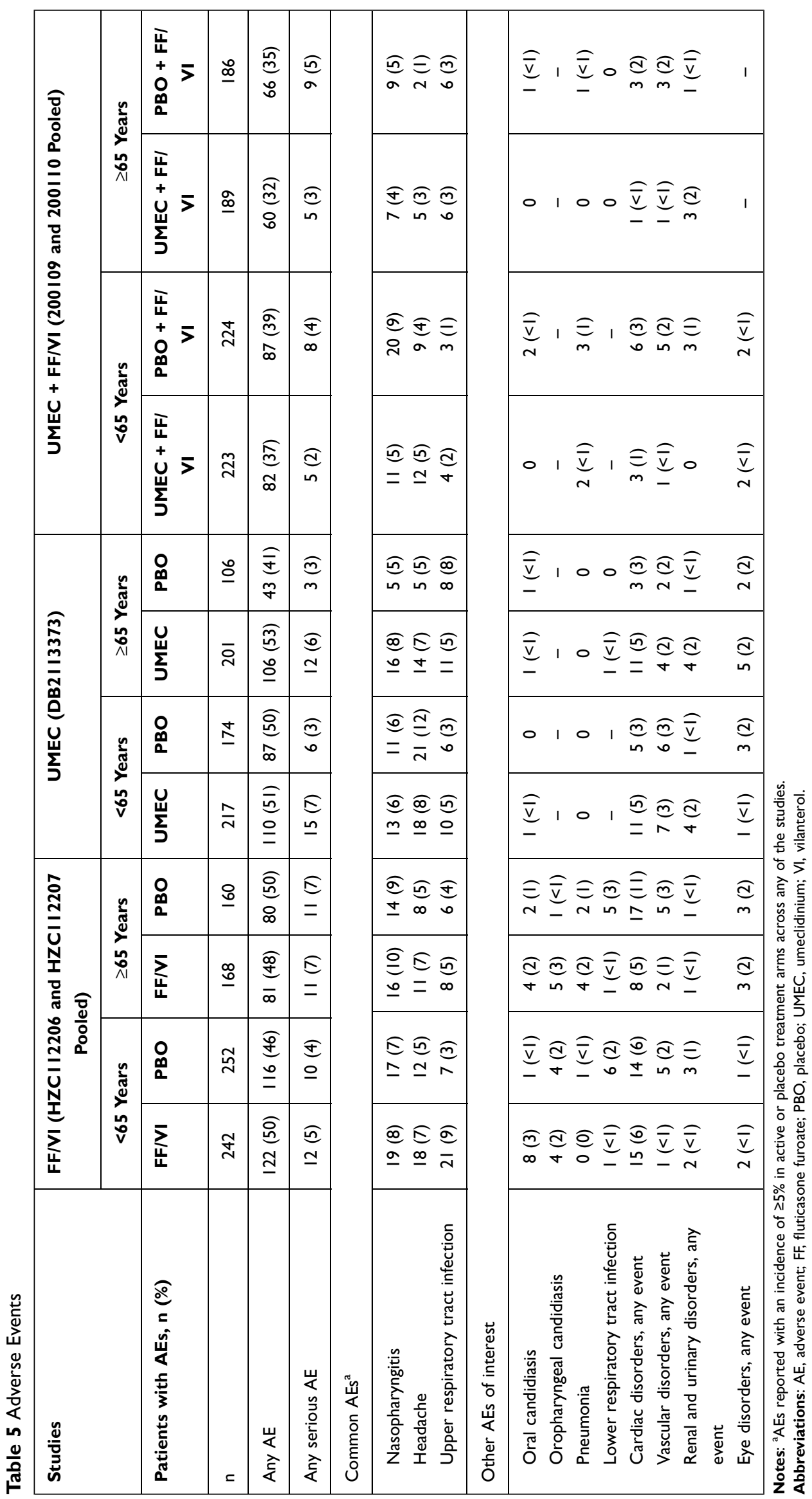


controlled trials, selection bias may have resulted in enrollment of patients with COPD who were healthier and had fewer comorbidities than the general COPD population, particularly in the older subgroup, potentially limiting the generalizability of our results. Detailed comorbidity data were not available in the studies analyzed so it has not been possible to investigate the impact of comorbidities on treatment response. The majority of patients in this analysis did not have an exacerbation in the past year and patients with other respiratory disease were excluded, therefore the results may not be generalizable to patients with frequent COPD exacerbations nor patients with other respiratory diseases. Also, longer-term studies are required to investigate the effect of age on the longerterm efficacy and safety of FF/VI, UMEC and UMEC + FF/VI. Furthermore, there were insufficient numbers of patients to analyze older subgroups (ie, $\geq 75$ years), who may be further impacted by comorbidities such as sarcopenia. Future studies should also consider including analyses by clinical phenotypes to facilitate personalized COPD treatment. ${ }^{26}$ Finally, our analyses did not consider other clinically meaningful outcomes for older populations, such as symptoms, quality of life, or exacerbations.

\section{Conclusions}

These data provide evidence of improved lung function with FF/VI, UMEC, and UMEC + FF/VI, all delivered via the ELLIPTA DPI, compared with placebo in both older $(\geq 65$ years) and younger ( $<65$ years) patients. As expected, the lung function benefit of the ICS/LABA FF/VI in older patients appeared to be primarily driven by the LABA, VI. The safety profile of each regimen, including the incidence of AEs of interest (such as cardiovascular events, renal/urinary events and pneumonia) was similar across age groups.

\section{Abbreviations}

AE, adverse event; BD, bronchodilator; CI, confidence interval; COPD, chronic obstructive pulmonary disease; $\mathrm{DPI}$, dry-powder inhaler; $\mathrm{FEV}_{1}$, forced expiratory volume in 1 second; FF, fluticasone furoate; FVC, forced vital capacity; ICS, inhaled corticosteroid; ITT, intent-to-treat; LABA, long-acting $\beta_{2}$-agonist; LAMA, long-acting muscarinic antagonist; LS, least squares; MITT, multipleinhaler triple therapy; OR, odds ratio; PBO, placebo; SD, standard deviation; SE, standard error; UMEC, umeclidinium; VI, vilanterol; WM, weighted mean.

\section{Data Sharing Statement}

Anonymized individual participant data and study documents can be requested for further research from www. clinicalstudydatarequest.com.

\section{Ethics Approval and Informed Consent}

All studies were conducted in accordance with the Declaration of Helsinki and were approved by the relevant local ethics review committees (Supplementary Table 2). All patients provided written, informed consent before study participation.

\section{Consent for Publication}

Patient consent is not required as all data are anonymized.

\section{Acknowledgments}

Editorial support (in the form of writing assistance, assembling figures, collating author comments, grammatical editing, and referencing) was provided by Katie White, $\mathrm{PhD}$, of Fishawack Indicia Ltd, UK, part of Fishawack Health, and was funded by GSK.

\section{Author Contributions}

All authors made a significant contribution to the work reported, whether that is in the conception, study design, execution, acquisition of data, analysis and interpretation, or in all these areas; took part in drafting, revising or critically reviewing the article; gave final approval of the version to be published; have agreed on the journal to which the article has been submitted; and agree to be accountable for all aspects of the work. NAH, DMM, and HP were involved in the data analysis and interpretation. TS, SC, IHB, CC, and SL were involved in the conception and design of the study and data analysis and interpretation. LT was involved in the conception and design of the study, acquisition of the data, and data analysis and interpretation.

\section{Funding}

This analysis and the original studies were funded by GlaxoSmithKline (GSK HZC112206 [NCT01053988], HZC112207 [NCT01054885], DB2113373 [NCT01313650], 200109 [NCT01957163], 200110 [NCT02119286]). GSK was involved in the study design; the collection, analysis and interpretation of the data; and the writing of the manuscript. 


\section{Disclosure}

NAH has received personal fees from GSK, AstraZeneca, Boehringer Ingelheim, Sanofi Genzyme, Novartis, Regeneron, Genentech, Teva, Amgen, Sunovion, and Mylan for serving as an advisor or consultant. He also received grants research support from Gossamer Bio, GSK, Boehringer Ingelheim, and AstraZeneca. TS, SL, CC, HP and IHB are employees of GSK and hold stock and shares in GSK. SC and DMM were employees of GSK at the time of the study and hold stock and shares in GSK. SC is currently an employee of Dermavant since April 2020. LT is a contingent worker on assignment at GSK. ELLIPTA is owned by/licensed to the GSK group of companies.

\section{References}

1. Buist AS, McBurnie MA, Vollmer WM, et al. International variation in the prevalence of COPD (The BOLD Study): a population-based prevalence study. Lancet. 2007;370(9589):741-750. doi:10.1016/ S0140-6736(07)61377-4

2. Sullivan J, Pravosud V, Mannino DM, Siegel K, Choate R, Sullivan T. National and state estimates of COPD morbidity and mortality - United States, 2014-2015. Chronic Obstr Pulm Dis. 2018;5(4):324-333. doi:10.15326/jcopdf.5.4.2018.0157

3. Fried TR, Vaz Fragoso CA, Rabow MW. Caring for the older person with chronic obstructive pulmonary disease. JAMA. 2012;308 (12):1254-1263. doi:10.1001/jama.2012.12422

4. Mangoni AA, Jackson SHD. Age-related changes in pharmacokinetics and pharmacodynamics: basic principles and practical applications. Br J Clin Pharmacol. 2004;57(1):6-14. doi:10.1046/ j.1365-2125.2003.02007.x

5. Hanania NA, Sharma G, Sharafkhaneh A. COPD in the elderly patient. Semin Respir Crit Care Med. 2010;31(05):596-606. doi:10.1055/s-0030-1265900

6. Taffet GE, Donohue JF, Altman PR. Considerations for managing chronic obstructive pulmonary disease in the elderly. Clin Interv Aging. 2014;9:23-30. doi:10.2147/CIA.S52999

7. Turan O, Turan PA, Mirici A. Parameters affecting inhalation therapy adherence in elderly patients with chronic obstructive lung disease and asthma. Geriatr Gerontol Int. 2017;17(6):999-1005. doi:10.1111/ ggi. 12823

8. Jarvis S, Ind PW, Shiner RJ. Inhaled therapy in elderly COPD patients; time for re-evaluation? Age Ageing. 2007;36(2):213-218. doi:10.1093/ageing/afl174

9. Bourgeois FT, Olson KL, Tse T, Ioannidis JP, Mandl KD. Prevalence and characteristics of Interventional Trials conducted exclusively in elderly persons: a cross-sectional analysis of Registered Clinical Trials. PLoS One. 2016;11(5):e0155948. doi:10.1371/journal. pone. 0155948

10. Anathhanam S, Powis RA, Cracknell AL, Robson J. Impact of prescribed medications on patient safety in older people. Ther Adv Drug Saf. 2012;3(4):165-174. doi:10.1177/2042098612443848

11. Ray R, Tombs L, Asmus MJ, et al. Efficacy of Umeclidinium/ Vilanterol in elderly patients with COPD: a pooled analysis of Randomized Controlled Trials. Drugs Aging. 2018;35(7):637-647. doi:10.1007/s40266-018-0558-y
12. Sutton L, Baylis LE, Jain R, Collison K, Mannino D, Patel P. Ease and correct use of ELLIPTA by age in patients with asthma and COPD. Chest. 2018;154(4):745A-746A. doi:10.1016/j.chest.2018.08.673

13. Kerwin EM, Scott-Wilson C, Sanford L, et al. A randomised trial of fluticasone furoate/vilanterol $(50 / 25 \mu \mathrm{g} ; 100 / 25 \mu \mathrm{g})$ on lung function in COPD. Respir Med. 2013;107(4):560-569. doi:10.1016/j. rmed.2012.12.014

14. Kerwin EM, Scott-Wilson C, Sanford L, et al. Corrigendum to "A randomised trial of fluticasone furoate/vilanterol (50/25 $\mu \mathrm{g} ; 100 / 25$ $\mu \mathrm{g}$ ) on lung function in COPD" [Respir Med, 107 (2013) 560-569]. Respir Med. 2013;107(12):2094. doi:10.1016/j.rmed.2013.10.008

15. Martinez FJ, Boscia J, Feldman G, et al. Fluticasone furoate/vilanterol $(100 / 25 ; 200 / 25 \mu \mathrm{g})$ improves lung function in COPD: a randomised trial. Respir Med. 2013;107(4):550-559. doi:10.1016/ j.rmed.2012.12.016

16. Martinez FJ, Boscia J, Feldman G, et al. Corrigendum to "Fluticasone furoate/vilanterol $(100 / 25 ; 200 / 25 \mu \mathrm{g})$ improves lung function in COPD: a randomised trial" [Respir Med 107 (2013) 550-559]. Respir Med. 2013;107(12):2092-2093. doi:10.1016/j.rmed.2013.10.009

17. Donohue JF, Maleki-Yazdi MR, Kilbride S, Mehta R, Kalberg C, Church A. Efficacy and safety of once-daily umeclidinium/vilanterol 62. 5/25mcg in COPD. Respir Med. 2013;107(10):1538-1546. doi:10.1016/j.rmed.2013.06.001

18. Siler TM, Kerwin E, Sousa AR, Donald A, Ali R, Church A. Efficacy and safety of umeclidinium added to fluticasone furoate/vilanterol in chronic obstructive pulmonary disease: results of two randomized studies. Respir Med. 2015;109(9):1155-1163. doi:10.1016/j.rmed.2015.06.006

19. Kerstjens HA, Rijcken B, Schouten JP, Postma DS. Decline of FEV1 by age and smoking status: facts, figures, and fallacies. Thorax. 1997;52(9):820-827. doi:10.1136/thx.52.9.820

20. Kohansal R, Martinez-Camblor P, Agustí A, Buist AS, Mannino DM, Soriano JB. The natural history of chronic airflow obstruction revisited: an analysis of the Framingham offspring cohort. Am J Respir Crit Care Med. 2009;180(1):3-10. doi:10.1164/rccm.200901-0047OC

21. Grant AC, Walker R, Hamilton M, Garrill K. The ELLIPTA ${ }^{\circledR}$ dry powder inhaler: design, functionality, in vitro dosing performance and critical task compliance by patients and caregivers. J Aerosol Med Pulm Drug Deliv. 2015;28(6):474 485. doi:10.1089/jamp.2015.1223

22. Hamilton M, Leggett R, Pang C, Charles S, Gillett B, Prime D. In vitro dosing performance of the ELLIPTA $^{\circledR}$ Dry powder inhaler using asthma and COPD patient inhalation profiles replicated with the electronic lung (eLung $\left.{ }^{\mathrm{TM}}\right)$. J Aerosol Med Pulm Drug Deliv. 2015;28(6):498-506. doi:10.1089/jamp.2015.1225

23. Prime D, de Backer W, Hamilton M, et al. Effect of disease severity in asthma and chronic obstructive pulmonary disease on inhalerspecific inhalation profiles through the ELLIPTA ${ }^{\circledR}$ dry powder inhaler. J Aerosol Med Pulm Drug Deliv. 2015;28(6):486-497. doi:10.1089/jamp.2015.1224

24. Altman P, Wehbe L, Dederichs J, et al. Comparison of peak inspiratory flow rate via the Breezhaler ${ }^{\circledR}$, Ellipta ${ }^{\circledR}$ and HandiHaler ${ }^{\circledR}$ dry powder inhalers in patients with moderate to very severe COPD: a randomized cross-over trial. BMC Pulm Med. 2018;18(1):100. doi:10.1186/s12890-018-0662-0

25. Hanania NA, Mannino DM, Criner GJ, et al. Effect of age on the efficacy and safety of once-daily single-inhaler triple therapy fluticasone Furoate/Umeclidinium/Vilanterol in patients with chronic obstructive pulmonary disease: a post hoc analysis of the IMPACT Trial. Chest. 2021;159:985-995. doi:10.1016/j.chest.2020.09.253

26. Montuschi P, Malerba M, Santini G, Miravitlles M. Pharmacological treatment of chronic obstructive pulmonary disease: from evidence-based medicine to phenotyping. Drug Discov Today. 2014;19(12):1928-1935. doi:10.1016/j.drudis.2014.08.004 


\section{Publish your work in this journal}

The International Journal of COPD is an international, peer-reviewed journal of therapeutics and pharmacology focusing on concise rapid reporting of clinical studies and reviews in COPD. Special focus is given to the pathophysiological processes underlying the disease, intervention programs, patient focused education, and self management protocols. This journal is indexed on PubMed Central, MedLine and CAS. The manuscript management system is completely online and includes a very quick and fair peer-review system, which is all easy to use. Visit http://www.dovepress.com/testimonials.php to read real quotes from published authors.

Submit your manuscript here: https://www.dovepress.com/international-journal-of-chronic-obstructive-pulmonary-disease-journal 